\title{
THE DEFLOCCULATION OF KAOLINITE SUSPENSIONS AND THE ACCOMPANYING CHANGE-OVER FROM POSITIVE TO NEGATIVE CHLORIDE ADSORPTION
}

\author{
By R. K. Schofield and H. R. SAmSON * \\ Read 7th November, 1952
}

It is surprising how reluctant many clay mineralogists have been to attribute the small cation exchange capacity of kaolinite to a correspondingly small isomorphous replacement. After all, only one silicon in 400 need be replaced by aluminium to give an exchange capacity of $2 \mathrm{~m} . e . / 100 \mathrm{gm}$., and it is very difficult to prove or disprove so small a replacement by chemical analysis.

The popular view is that the negative charges are all situated on the edge faces of the kaolinite crystals and are due to "broken bonds". This idea appeared to receive support from the increase in exchange capacity caused by grinding, until it was realised that such grinding disorganises some of the lattice. If in this disorganisation some aluminium is forced into four co-ordination this would be enough to account for the increase in exchange capacity. There is no satisfactory evidence for the view that the exchange capacity of unground kaolinite is proportional to the area of edge faces.

Hendricks (1945) deduced from the crystal structure that the oxygens at the edge of a silicon oxygen sheet, being bonded to only one silicon, will each carry one negative charge, while the corresponding pair of oxygens at the edge of the gibbsite layers, each of which is bonded to hydrogen or silicon and (by a half bond) to one aluminium, will carry one half negative charge. He therefore concluded that each $33 \AA^{2}$ of regular edge face will carry two negative charges (one whole plus two halves). This conclusion overlooked the possibility that these edge oxygens can form additional bonds to hydrions.

Now we can be sure that all the oxygens at the edges of the silicon oxygen sheets could remain negatively charged only at very high $\mathrm{pH}$ values. In neutral and acid conditions practically all will be combined with hydrions to form uncharged hydroxyls. There is also the possibility that the oxygens at the edges of the gibbsite layers can each combine with a hydrion. If this happens the balance of charge on each of these oxygens is plus one half, and these together make one plus charge per $33 \AA^{2}$. (Fig. 1.) While we have still to establish that this happens quantitatively it is quite evident from our measurements and observations that the edge faces of kaolinite are positively charged in acid conditions.

\footnotetext{
* Commonwealth Scientific \& Industrial Reseach Organisation, Melbourne.
} 
ModeratelyAcid Very slightly alkaline Strongly Alkaline

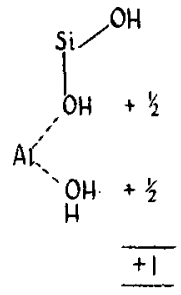

(a)

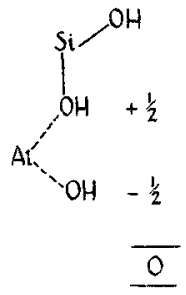

(b)

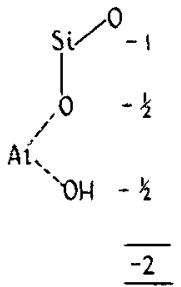

(c)

Frg. 1. Hydrions attached to oxygens at the edge faces of kaolinite when the suspending solution is (a) acid, (b) slightly alkaline, (c) strongly alkaline.

Now when clay minerals are acidified by electrodialysis or by washing with dilute hydrochloric acid, aluminium is liberated, and the precipitation of this aluminium as hydroxide dominates the buffer curve when the so-called "hydrogen clay" is titrated with alkali. To avoid or at least minimise this complication, we have treated all our kaolin samples with normal sodium chloride containing thousandth normal hydrochloric acid in the belief that this removes all or most of the aluminium already outside the kaolinite lattice, and, at the same time, causes little or no further breakdown. After washing out the salt we are then left with a kaolinite retaining exchangeable sodium, for, although the edge faces carry positive charges, these offset only a part of the negative charges (due presumably to isomorphous replacement), and the sodium ions thus balance the net negative charge which is still there even in this acid condition.

The removal of aluminium external to the kaolinite lattice reduces but does not eliminate the buffer capacity. Titration with sodium hydroxide in extremely dilute sodium chloride gives a buffer curve with a distinct inflexion on the alkaline side of the neutral point. The evidence which we will present permits us to connect this point of inflexion with the condition of the edge faces in which only one of each pair of the edge oxygens of the gibbsite layer is bonded to an additional hydrion. So while this oxygen carries a half positive charge, the other carries a half negative charge.

Hence in this condition the edge faces are uncharged, but there still remain the negative charges situated within the lattice of the crystals due to isomorphous replacements. These negative charges are permanent in the sense that they cannot be changed reversibly by change in $\mathrm{pH}$, whereas the sign and magnitude of the charges on the edge faces definitely depend on $\mathrm{pH}$ and salt concentration. 
In this paper we are talking about kaolinite, but we have good reason to think that essentially the same picture applies to montmorillonite and illite also.

Following up earlier work (Schofield, 1947, 1949) we have succeeded in measuring the very small adsorption of chloride which occurs at the surface of kaolinite. The results shed new light on the flocculation of kaolinite and show the dominant rôle which positively charged edge faces can play in this phenomenon.

A sample of kaolinite containing no detectable amounts of other clay minerals was leached several times with a $1 \mathrm{~N}$ solution of $\mathrm{NaCl}$, containing $1 \times 10^{-3} \mathrm{~N} \mathrm{HCl}$ until practically no aluminium was detected in the leachate. The salt was then washed out with distilled water. It was possible to wash the clay until free of chloride and in this condition the material remained flocculated.

When illite or montmorillonite was pre-treated in exactly the same manner, spontaneous deflocculation occurred when the $\mathrm{NaCl}$ concentration was reduced below a certain critical value. Here, then, is a clear distinction between the dispersion behaviour of kaolinite on the one hand and of montmorillonite and illite on the other. This distinction was recognised by Marshall (1931), but its significance has not since been appreciated.

As is well known, kaolinite suspensions may be deflocculated by the addition either of $\mathrm{NaOH}$ or, if $\mathrm{Ca}^{+}++$is present, by $\mathrm{Na}$ silicate or $\mathrm{Na}$ polymetaphosphate. The point of deflocculation is conveniently fixed by measurements of apparent viscosity, and is characterised by an extremely sudden drop in apparent viscosity to a value not much in excess of the viscosity of water. The actual decrease may amount to as much as one thousandfold, depending on the particle size distribution, concentration of suspension, particle shape and type of viscometer. In this work, a simple torsion viscometer, previously calibrated against solutions of known viscosity, was employed. Chloride determinations were carried out by the differential titration method of MacInnes and Dole (1929), using two (silver)-(silver chloride) electrodes. The kaolinite was suspended in distilled water, and a quantity of $\mathrm{NaOH}$ just insufficient to cause complete deflocculation was added. The final washing removed the last traces of chloride, and after filtration and drying at $105^{\circ} \mathrm{C}$ this clay was used as the starting material for chloride adsorption measurements. Weighed portions of kaolinite were suspended in a series of $\mathrm{N} / 200 \mathrm{NaCl}$ solutions to which graded amounts of $\mathrm{HCl}$ and $\mathrm{NaOH}$ were added, and the increase or decrease in chloride concentration was determined by analysis of the clear liquid obtained by centrifuging.

A typical set of results is shown in Fig. 2. After the addition of a small quantity of $\mathrm{HCl}$, sufficient to reduce the $\mathrm{pH}$ of the suspension 


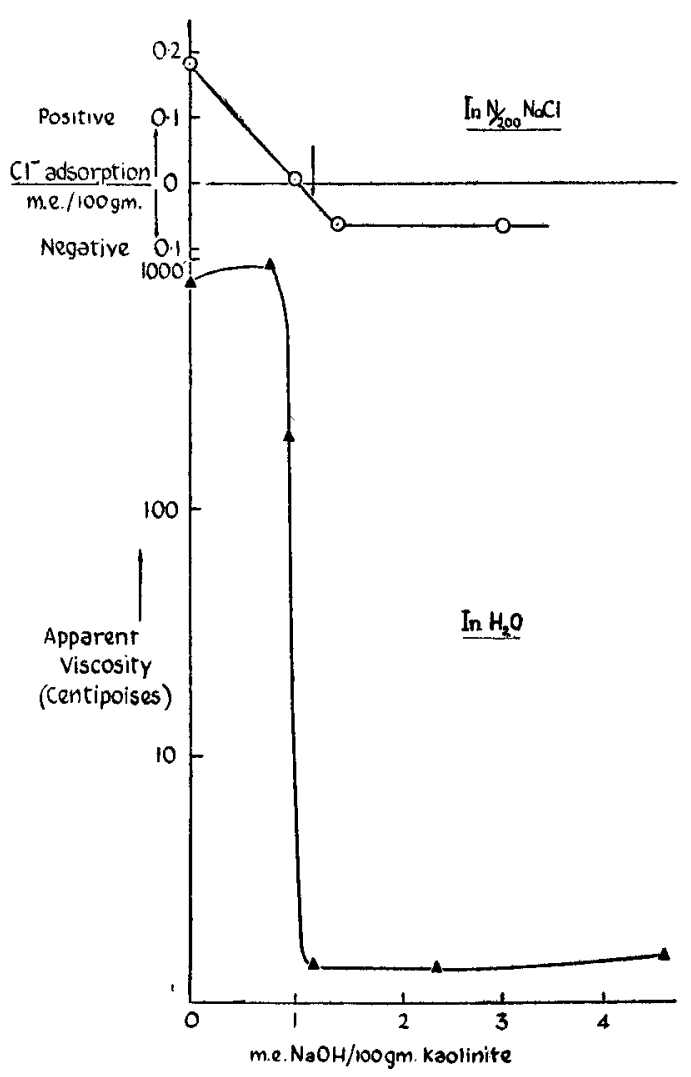

F1G. 2. Chloride adsorbed by various kaolinites when added with $\mathrm{NaOH}$ or $\mathrm{HCl}$ to $\mathrm{N} / 200 \mathrm{NaCl}$ solution. Arrows indicate amounts of $\mathrm{NaOH}$ needed to cause deflocculation of salt-free suspensions.

to 5 , the clay retained chloride ions; positive adsorption had occurred. On the alkaline side, however, an increase in chloride concentration was observed, indicating that the kaolinite particles had repelled chloride ions, i.e. the adsorption had become negative. Since kaolinite maintains a net negative charge down to low $\mathrm{pH}$ values, most of this negative adsorption may be assumed to operate over the whole range. Below a certain $\mathrm{pH}$, which is close to 9.0 in the presence of $\mathrm{N} / 200 \mathrm{NaCl}$, there evidently exist positive charges, which are capable of retaining chloride ions and thus masking the negative adsorption effect. $\mathrm{As}$ the $\mathrm{pH}$ is increased, the number of these positive charges evidently decreases, and finally they disappear. The full negative adsorption is then measurable; it attains a constant value, and from it the surface area of the kaolinite may be calculated. Fig. 3 shows the data for several different samples. 


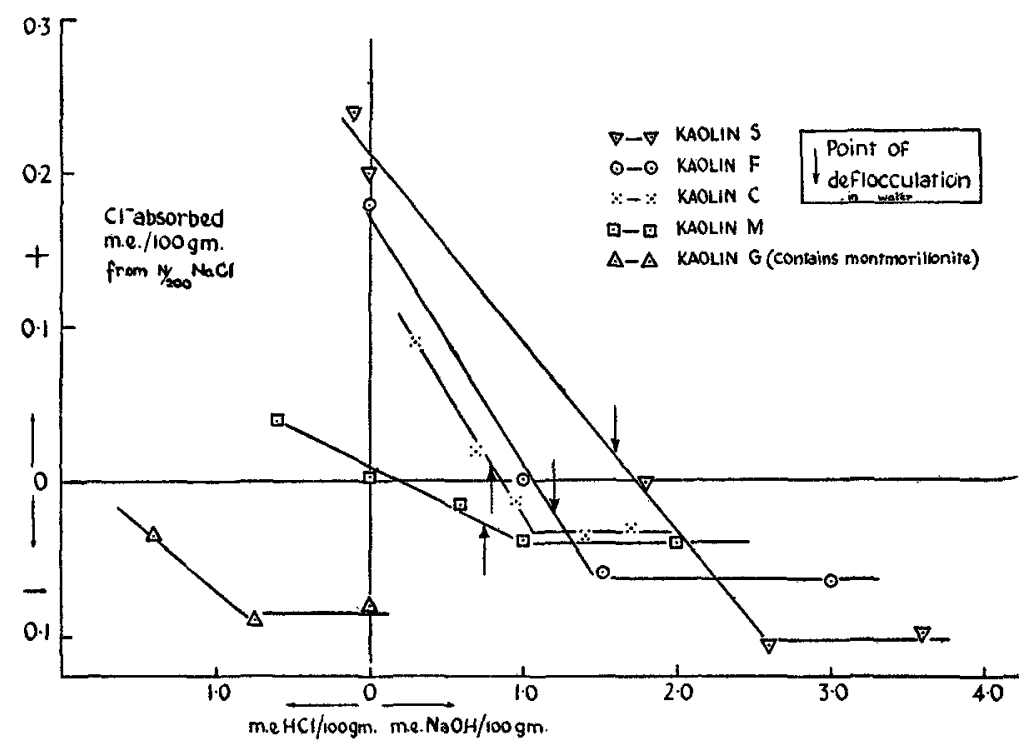

FIG. 3. Change-over from positive to negative chloride adsorption in $N / 200$ $\mathrm{NaCl}$ solutions and from flocculation to deflocculation in salt-free aqueous suspensions.

What is the relation of this to deflocculation? At about the point where the positive adsorption balances the negative adsorption, measured in $\mathrm{N} / 200 \mathrm{NaCl}$, the kaolinite is in the condition where it deflocculates in a salt-free suspension. When a certain critical amount of $\mathrm{NaOH}$ is added, the number of positive charges is reduced to the point where the edge faces on which they occur are no longer capable of attracting the negatively charged cleavage surfaces of adjacent crystals. The inter-particle repulsive forces, due to the net negative charge, are then adequate to maintain complete dispersion. The edge-to-face type of flocculation would be expected to give rise to large flocs, rapid settling and a particularly voluminous sediment. Such behaviour is characteristic of the $\mathrm{Na}^{+}$kaolinite before the addition of $\mathrm{NaOH}$.

One particular kaolin, which contained a very small amount of montmorillonite as judged by X-ray examination, proved to be of special interest. Its behaviour was anomalous in that after $\mathrm{NaCl}$ $\mathrm{HCl}$ treatment, spontaneous deflocculation occurred when the electrolyte concentration was reduced. The kaolin, in effect, behaved as did illite and montmorillonite. Furthermore in this condition the maximum negative adsorption was observed, and from this value the calculated specific surface was $18 \mathrm{~m}^{2} / \mathrm{gm}$., which is in quite good agreement with the area determined by $\mathrm{N}_{2}$ adsorption, i.e. $16 \mathrm{~m}^{2} / \mathrm{gm}$. This information was kindly supplied by Dr. S. J. Gregg. 
The conclusion seems inescapable that in this condition there were no positively charged areas on the kaolinite particles. The interpretation offered is that the small negatively charged montmorillonite platelets, which under these conditions are only $10 \AA$ in thickness, are attracted to and held by the edge faces of the much larger kaolinite crystals, thereby neutralising their positive charge. Chloride ions are no longer adsorbed, neither is there any attraction between edges and cleavage faces of adjacent kaolinite particles.

The following procedure was adopted to remove the montmorillonite. A portion of the clay was suspended in water containing enough $\mathrm{NaOH}$ to bring the $\mathrm{pH}$ to about 10 , and the suspension centrifuged. Under these conditions, not only have the positive charges disappeared but, in addition, extra negative charges are developed at the edges according to the reaction:-

$$
\equiv \mathrm{Si}-\mathrm{OH}+\mathrm{OH}^{-} \rightarrow \equiv \mathrm{Si}-\mathrm{O}^{-}+\mathrm{H}_{2} \mathrm{O} .
$$

After several centrifugings and decantations to remove the montmorillonite and, unavoidably, some of the finest kaolinite, the residual clay was treated with $\mathrm{NaCl}-\mathrm{HCl}$, as before, and the salt washed out. The kaolinite then remained flocculated.

The reverse effect was observed after adding a small amount of a dilute $\mathrm{Na}^{+}$-montmorillonite or $\mathrm{Na}+$-illite suspension to a flocculated $\mathrm{Na}^{+}$-kaolinite. The streaming birefringence characteristic of complete dispersion immediately became apparent. It is believed that a similar mechanism may account for the effectiveness of certain anions, particularly polyanions, in causing deflocculation. There is already evidence of a marked decrease in positive chloride adsorption by a kaolin which has been pre-treated with $\mathrm{Na}$ alginate or Na polymetaphosphate, and further work along these lines is in progress.

Acknowledgement.-We are indebted to $\mathrm{Mr} \mathrm{G}$. Brown for his careful X-ray examination of the kaolinites.

Rothamsted Experimental Station, Harpenden, Herts.

\section{References.}

Hendricks, S. B., 1945. Ind. Eng. Chem., 37, 625.

MacInnes, D. A. and Dole, M., 1929. J. Amer. Chem. Soc., 51, 1119.

Marshall, C. E., 1931. J. Soc. Chem. Ind., (Trans.), 50, 457T.

Schofield, R. K., 1947. Nature, 160, 408. 1949. Trans. Brit. Ceram. Soc., 48, 207. 


\section{Discussion.}

Mr Greene-Kelly.-During the preparation of clay fractions from crude materials for mineralogical examination, it is often the practice to use calgon or alkali to disperse the clay. This would appear to favour the dispersion of kaolin minerals since calciumsaturated montmorillonite minerals are not dispersed by calgon. In consequence, quantitative analysis of the resultant small size fraction may bear little relation to the true composition of the clay. I suggest that sodium saturation should be an essential part of the treatment used to prepare the crude material for dispersal.

Dr MacEwan.-There is one interesting point and that is in connection with alleged hydroxyl groups in the structure of montmorillonite. Edelman and Favejee originally proposed that it is necessary to have $\mathrm{OH}$ groups attached to silicon to supply protons for base exchange. The authors of this paper suggest that such groups would not in principle be capable of dissociating at neutral pH's at all. If this is so, it removes the theoretical basis for the Edelman-Favejee postulate. 